\title{
Bayesian and parsimony phylogeny of Augochlora bees (Hymenoptera: Apoidea) based on morphology: insights for their biogeography and natural history
}

\author{
Anderson Lepeco, Rodrigo Barbosa Gonçalves \\ Departamento de Zoologia, Universidade Federal do Paraná, Cx. Postal 19020, 81531-980, Curitiba, PR, Brazil \\ http://zoobank.org/F730F684-CC13-432B-8480-89D91999F601
}

Corresponding author: Anderson Lepeco (al.lepeco@gmail.com)

Received 21 July 2021

Accepted 10 January 2022

Published 04 March 2022

Academic Editors Brian Wiegmann, Anna Hundsdörfer

Citation: Lepeco A, Gonçalves RB (2022) Bayesian and parsimony phylogeny of Augochlora bees (Hymenoptera: Apoidea) based on morphology: insights for their biogeography and natural history. Arthropod Systematics \& Phylogeny 80: 99-115. https://doi.org/10.3897/asp.80.e71943

\begin{abstract}
Augochlora Smith, with 127 valid species, is the most widespread genus of Augochlorini bees, ranging from Argentina to southern Canada, including the Caribbean islands. The genus is divided into three subgenera, Augochlora s. str., Oxystoglossella Eickwort, and the fossil Electraugochlora Engel. The extant subgenera were traditionally diagnosed by their nesting substrate, social behavior and morphology. However, accumulating evidence suggests that these features are not reliable for their separation, especially with the discovery of an enigmatic species sharing characteristics from both subgenera. Our objective is to provide a phylogenetic hypothesis to evaluate the monophyly of the extant subgenera and to place a new species, Augochlora (Augochlora) intermedia sp. nov. For this purpose, we compiled 110 unordered characters for 40 species of Augochlora plus seven outgroup species and analyzed under parsimony and Bayesian inference. Topologies were very similar under both frameworks, allowing us to consistently characterize a few major lineages. Our results demonstrate that the extant subgenera correspond to monophyletic groups and the new species is sister group to remaining Augochlora s. str. species. Both subgenera are widespread in the Western Hemisphere, with species groups differing in range and distributional patterns. Our interpretation is that Augochlora arose in South America, subsequently colonizing Mesoamerica, the Caribbean and North America several times. Facultative social behavior can be found in both subgenera and in most lineages, indicating that the exclusive solitary behavior found in Augochlora pura is an exception. Based on morphological clues we interpret that the habit of nesting out of the soil arose once in Augochlora s. str.
\end{abstract}

\section{Keywords}

Augochlorini, Biogeography, Halictidae, Homoplasy, Neotropical, Partitioning

\section{Introduction}

Augochlorini Beebe is restricted to the western hemisphere, representing a major component of the Neotropical bee fauna (Eickwort 1969; Danforth and Eickwort 1997; Engel 2000; Pinheiro-Machado et al. 2002). These bees are remarkable among other Halictinae by their diversity of specializations, embracing both behavioral and morphological aspects. The tribe is mostly composed of soil-nesting diurnal species, but nocturnal/crepuscular 
behavior, cleptoparasitism and capacity of using decaying wood as nesting substrate are often found among its representatives (Eickwort 1969; Michener 1990, 2007; Engel 2000). Each of these characteristics evolved independently at least two times in different lineages within the tribe, somewhere during the Cenozoic (Gonçalves 2016). These bees also exhibit many levels of social organization, including solitary species with small nests and primitively eusocial species with large multifemale nests (Michener and Lange 1958; Ordway 1965; Stockhammer 1966; Danforth and Eickwort 1997; Gonzalez et al. 2014). Such behavioral diversity is often linked with morphological adaptations, for example the allometric growth of cephalic structures in some females of eusocial species, enlargement of eyes and ocelli in crepuscular or nocturnal species, and well-developed ridges on mandibles of females that build nests within wood (Sakagami and Moure 1965; Eickwort 1969; Gonçalves and Melo 2012; Lepeco and Gonçalves 2018). Even though many of these aspects have been investigated since the last century, the elucidation of their evolutionary pathways is still unclear, since species-level phylogenies are lacking for the speciose genera.

Augochlora Smith is the most widespread genus of Augochlorini, ranging from the province of Neuquén in central Argentina to southern provinces of Canada (Engel 2000; Packer et al. 2007; Lepeco and Gonçalves 2020a), being one of the few lineages of the tribe occurring in the Caribbean islands (Eickwort 1969; Engel 2000; Michener 2007). In the Neotropical region, these bees can be found in virtually all environments, with the exception of some xeric areas of Argentina and Chile (Dalmazzo and Roig-Alsina 2011). The diversity of Augochlora decreases in temperate regions with an apparent higher diversity in forested areas (Lepeco and Gonçalves 2020a). Presently, there are 127 valid species (Moure 2012; Ascher and Pickering 2021; Lepeco and Gonçalves 2020a, 2020b; this study), a number only outreached by Augochloropsis Cockerell within the tribe. Augochlora is a monophyletic group that belongs to the Augochlora genus group along with Augochlorella Sandhouse, Ceratalictus Moure and Pereirapis Moure (Engel 2000; Gonçalves 2016, 2019). The acute angle of epistomal sulcus and the truncate and appendiculate marginal cell apex are distinctive features of the genus (Eickwort 1969). According to Engel (2000) and Coelho (2004) Augochlora is related to Ceratalictus + Pereirapis, with Augochlorella as the sister group with the remaining genera, while Gonçalves $(2016,2019)$ considered Augochlora as sister group with Augochlorella.

Currently, the genus is divided in three valid subgenera: Augochlora s. str., Electraugochlora Engel, and Oxystoglossella Eickwort (Engel 2000; Michener 2007; Moure 2012), but other four genus group names are available. Smith (1853) described Augochlora and included diverse augochlorine bees, mostly species currently placed in Augochloropsis. Later, Cockerell (1923) designated Augochlora pura (Say, 1837) as the type species of Augochlora and then Sandhouse (1937) properly delimited the genus as recognized by subsequent authors. Before 1937 the Augochlora species were placed on Oxystoglossa
Smith or Odontochlora Schrottky. Oxystoglossa was proposed by Smith in the description of Augochlora decorata (Smith, 1853) and this name was used by some authors (e.g., Schrottky 1909b) for Augochlora species without a spine in the first metasomal sternum. Posteriorly, Schrottky (1909a) proposed the subgenus Odontochlora for $\mathrm{Au}$ gochlora species with a projection on the first metasomal sternum, designating Augochlora mulleri (Cockerell, $1900)$ as the type species. Both genus names were synomyzed under Augochlora by Sandhouse (1937). Eickwort (1969) considered Augochlora repandirostris (Vachal, 1911) remarkably different from other Augochlora, due to the epistomal angle weakly produced and the clypeus apical margin prolonged, proposing Mycterochlora Eickwort as a subgenus to accommodate this and other similar species. Later, Mycterochlora was synonymysed with Augochlora s. str. by Engel (2000). Augochlora cordiaefloris Cockerell, 1907 is the type species of a second valid subgenus, Oxystoglossella, described by Eickwort (1969) to accommodate species with preapical tooth of mandibles not produced. The subgenus Aethochlora was proposed by Moure and Hurd (1987) mostly based on the enlarged gena of Augochlora matucanensis Cockerell, 1914, but this name was synonymized under Oxystoglossella by Engel (2000). The third subgenus, Electraugochlora was described by Engel (2000) for one fossil species, A. leptoloba Engel, 2000, which lacks the distinctive acute angle of epistomal sulcus.

A broad sample of the behavioral diversity found in Augochlorini is present also in Augochlora, since species have particular nesting substrate preferences and sorts of social organization (Michener and Lange 1958; Stockhammer 1966; Dalmazzo and Roig-Alsina 2012, 2015, 2018a, 2018b). Previously, it was believed that eusocial behavior was restricted to the subgenus Oxystoglossella, especially due to long-term observations of nests of the solitary A. (Augochlora) pura (Michener and Lange 1958; Stockhammer 1966; Eickwort and Eickwort 1972, 1973; Engel 2000). Posteriorly, it was noted that other Augochlora s. str. species exhibit eusociality (Wcislo et al. 2003; Dalmazzo and Roig-Alsina 2012, 2015, 2018a, 2018 b). In the primitively eusocial species, morphological variation among nestmates may be restricted to overall body size, as in A. (A.) phoemonoe (Schrottky, 1909), or with allometric growth of the head and its structures, as seen in A. (Oxystoglossella) iphigenia Holmberg, 1886 and $A$. (A.) daphnis Smith, 1853 (Dalmazzo and Roig-Alsina 2012, 2015; Lepeco and Gonçalves 2018). The phylogenetic placement of the genus within the $A u$ gochlora group of genera suggests a secondary loss of eusociality at least in A. (A.) pura, given that Augochlorella Sandhouse and Pereirapis Moure are eusocial as far as is known (Michener 1990; Wcislo and Danforth 1997). Nothing is known about the behavior of the species of Ceratalictus (Wcislo and Danforth 1997; Engel 2000).

Both subgenera apparently diverge in nesting substrate usage - Augochlora s. str. construct nests from cavities within soft wood, while all Oxystoglossella so far studied exhibit the ancestral soil-nesting behavior. A. (A.) esox is the only known species to nest within the hummus accu- 
mulated in the rosettes of bromeliads (Zillikens 2001), but this species was also collected nesting in wood. All known females of Augochlora s. str. have strongly bidentate mandibles with more conspicuous ridges on the outer surface, characteristics associated with excavation of soft wood (Eickwort 1969; Eickwort and Sakagami 1979). This trend is reinforced by the presence of even more developed mandibular ridges on larger females of some $\mathrm{Au}$ gochlora s. str., that may represent foundresses in charge of nesting construction (Dalmazzo and Roig-Alsina 2012, 2015; Lepeco and Gonçalves 2018). On the other hand, the preapical tooth of Oxystoglossella females is small and largely separated from the apex of the mandible. Both subgenera also may differ in the pubescence of the pseudo-pygidial area, which is considered as related to the differing nesting substrate preferences (Engel 2000; Wcislo et al. 2003; Michener 2007). In addition, nesting architecture may differ within subgenera, as some species do not construct cell clusters, differing from the typical nest architecture of most Augochlorini (Eickwort and Sakagami 1979; Wcislo et al. 2003).

Although regional taxonomic revisions and species descriptions have been made in recent years (see Dalmazzo and Roig-Alsina 2011; Engel et al. 2012; Genaro 2016; Lepeco and Gonçalves 2020a, 2020b), the subgeneric classifications were not properly evaluated. In the present study we describe a new species bearing a mosaic of morphological characteristics found in both subgenera and explore the morphological variation within Augochlora, in order to propose a phylogenetic hypothesis for its main extant lineages. With this hypothesis in mind, we thereby discuss its implications for interpreting macroevolutionary patterns of: biogeography, nesting substrate and architecture; and for social behavior and related morphological polymorphisms.

\section{Methods}

We selected 40 species of Augochlora as ingroup taxa, including all generic and subgeneric type species, with the exception of Augochlora (A.) decorata, whose type specimen is in poor conditions (images available in the British Natural History Museum website). We included seven species for the outgroups. Augochlorella comis (Vachal, 1911), Augochlorella ephyra (Schrottky, 1910), Ceratalictus clonius (Brèthes, 1909) and Pereirapis semiaurata (Spinola, 1853) as members of the Augochlora group of genera (Eickwort 1969; Engel 2000; Gonçalves 2016, 2019). We also included species of Augochlorini from other groups of genera, Pseudaugochlora graminea (Fabricius, 1804), Neocorynura codion (Vachal, 1904) and Thectochlora brachycera Gonçalves \& Melo, 2006. Males and females were coded for all terminals, with the exception of males of $A$. (A.) azteca (Vachal, 1911) and Augochlorella comis (Vachal, 1911), the latter being coded for as many characters as possible using the literature. Also, male genitalia information is lacking for $A$.
(O.) matucanensis Cockerell, 1914 and A. (O.) rightmyerae Engel, 2000. All specimens examined for the present analyses are permanently housed in the Coleção Entomológica Pe. Jesus Santiago Moure at the Departamento de Zoologia, Universidade Federal do Paraná (DZUP), Curitiba, Paraná, Brazil.

Morphological terminology follows Michener (2007) except for mandibular structure following Michener and Fraser (1978) and genital capsule following Eickwort (1969). We use the abbreviations F1, F2 etc. to denote antennal flagellomeres; T1, T2 etc., to denote the metasomal terga; and S1, S2 etc., to denote metasomal sterna. We measure setae length in comparison to mid ocellus diameter (OD) and punctures interspaces in comparison to puncture diameter (PD). To study male genitalia characters, specimens were softened in a wet chamber for two or three days. Genitalia were removed with entomological pins and clarified in $10 \% \mathrm{KOH}$ for 24 hours and then analyzed and preserved immersed in glycerol. Most of had type material of Augochlora intermedia sp. nov. is deposited in DZUP, with exception of one female paratype deposited in RPSP - Coleção Entomológica "Prof. J. M. F. Camargo", Universidade de São Paulo, Ribeirão Preto, Brazil. The species description, including measurements and sculpturing terminology follows Lepeco and Gonçalves (2020a, 2020b).

Specimens were examined under Olympus SZ51 and SZ61 microscopes, using led ring illumination. Measurements were taken with the aid of a micrometric rule coupled to a Leica Stemi DV4. Specimens were photographed with a Nikon D7000 with a 105 mm Sigma Macro lens, controlling image capture with Helicon Remote. The illumination techniques used were those suggested by Kawada and Buffington (2016). Image stacking was made using the software Helicon Focus (version 6.18), based on Method C (Pyramid). Final image adjustments, including unsharp mask filtering and level control, and plate design were made with GIMP 2.8.16 (CThe GIMP Team).

The morphological matrix was largely based on characters from previous studies (Engel 2000; Coelho 2004; Gonçalves 2016, 2019), with reinterpretations and additions where needed (Supplementary file 1: List of characters). The final matrix comprised 110 unordered characters and 47 terminals (Supplementary file 2: Morphological matrix). Inapplicable characters were coded with "--" and missing data with "?". For most of the terminals, more than one specimen was observed during character construction and coding processes. Construction of characters was based on the method proposed by Sereno (2007). Autapomorphic characters were included, since they are used in estimation of branch lengths under parametric frameworks (Lewis 2001).

Parsimony analyses were taken using new search methods (Goloboff et al. 2008), under the following settings in TNT software: ratchet weighting probability $5 \%$, 200 iterations, tree-drifting (50 cycles), and tree-fusing (five rounds, minimum length set to be hit 100 times). Analyses were conducted under equal weights and implied weighting, with different values for the concavity parameter $(k)$ tested. Since there were no significant 
alterations in tree topology under different $k$ values, we used the standard $k=3$ to calculate Goloboff's measure of homoplasy $(f)$. Bootstrap and Jackknife values (1000 replications) and Bremer support were also calculated using TNT. Trees were viewed and edited using WinClada 1.00.08 (Nixon 2002).

The original character matrix was partitioned using the $f$ values, following the methodology of Rosa et al. (2019). Final partitioning scheme comprised five partitions, with non-homoplastic and parsimony uninformative characters included in the same partition (Supplementary file 3: Partitioning scheme). We considered the minimum partition length $=6$, to ensure that each partition would include at least $5 \%$ of the characters and, thus, avoiding excessive partitioning of the dataset. Branch lengths were linked among partitions, exponential prior on branch lengths with scale parameter $=10$ and without assessment of site-specific rates within partitions. MCMC analyses were conducted in MrBayes 3.2.6 (Ronquist et al. 2012), using the Mk model accounting for ascertainment bias, since only variable characters were scored (lset coding $=$ variable $)$. The analysis ran for a total of 5.000.000 generations, sampling every 100th state and with four independent runs. Convergence was assessed with Tracer 1.6 (Rambaut et al. 2018) and majority-rule consensus trees (Contype $=$ Allcompat) were computed with TreeAnnotator. A similar analysis was conducted without partitioning the data, accounting for among-character rate heterogeneity using a discretized Gamma distribution with four rate categories.

\section{Results}

\subsection{Phylogenetic analyses}

All analyses recovered Augochlora as monophyletic with strong support values (Fig. 1) and high posterior probabilities (PP $>95$, Fig. 2, Supplementary file 4: Phylogenetic trees, Fig. 1). According to implied weighting and partitioned Bayesian analyses Augochlora is sister group to Augochlorella. However, unpartitioned Bayesian analysis found Augochlorella as the sister group to the remaining genera while Augochlora as related to Ceratalictus + Pereirapis (Supplementary file 4: Phylogenetic trees, Fig. 2 ) and parsimony under equal weights recovered a polytomy at this node (Supplementary file 4: Phylogenetic trees, Fig. 3). For simplification purposes, support values and posterior probabilities mentioned henceforward are based on results of the implied weighting parsimony and partitioned Bayesian analyses.

Both valid extant subgenera of Augochlora were recovered as monophyletic. The subgenus Oxystoglossella has 73 bootstrap and 80 jackknife support values (Fig. 1) and PP value equal to 0.95 (Fig. 2). Its synapomorphies are the pale yellowish hind basitarsus on males and the setae on the outer lobe of ventral gonostylus longer than inner lobe length (Fig. 1). The relationships among species are stable among analyses and two main clades are found, herein the A. iphigenia and A. morrae species groups. Each species group has three synapomorphies, with the basal elevation of the labrum slightly produced in A. iphigenia group and orbicular in A. morrae group. The $A$. iphigenia group $(\mathrm{PP}=0.96)$ is also defined by the broad mandible and not expanded preoccipital carina, and A. morrae group $(\mathrm{PP}=0.97)$ by slightly pointed hypostomal carina and long S7 pre-apodemal projection.

Augochlora s. str. have 72 bootstrap and 82 jackknife support values (Fig. 1) and PP value equal to 0.73 (Fig. 2). Its synapomorphies are the thin apical black band on clypeus and the metapostnotum about $1.5 x$ longer than metanotum, and the black basal area of the labrum (only at fast optimization). There are five major clades within Augochlora s. str. recognized here as species groups. Despite the low support values in the parsimony analysis, relationships among the species groups are relatively well supported in the Bayesian analysis (PP > 0.7). All species groups defined herein were stable among analyses and have posterior probabilities higher than 0.95 , with the exception of the A. pura species group. Augochlora (A.) intermedia sp. nov. has an isolated placement and is sister group to the remaining groups according to three out of four analyses (Fig. 1-2). The remaining Augochlora s. str. are grouped by three non-homoplastic synapomorphies: preapical tooth of mandible sharp and produced near apex of mandible, pseudo-pygidial area without appressed scale-like setae, and T1 with a relatively large impunctate area near apical dark band. On the other hand, the unpartitioned Bayesian analysis recovered the $A$. hestia species group as the sister group with the remaining $A u$ gochlora s. str. (Supplementary file 4: Phylogenetic trees, Fig. 2). This group has a strong support $(P P=1)$ and several synapomorphies, including the orbicular elevation and yellowish basal area of labrum, features shared with some Oxystoglossella. Also, females in this group have a flattened mesofemur, with a characteristic depression near the brush posteriorly.

The remaining Augochlora s. str. species are grouped by the presence of a long dark area between the premarginal setae apex and the T3 apex, the acute shape of apical spine on outer surface of hind tibia, and by the S2 apex acute medially on males (Fig. 1). The presence of a median longitudinal impression on the scutellum is a synapomorphy of the A. daphnis species group ( $\mathrm{PP}=$ 0.98), being valuable to diagnose the group. Another synapomorphy for this group is the angulation between the anterior and posterior surfaces of the hind coxae, sometimes forming a slight longitudinal carina, a condition also found in $A$. (A.) intermedia sp. nov. The $A$. repandirostris species group has strong support $(\mathrm{PP}=1)$ and several synapomorphies, some of them useful to readily distinguish its species, such as the projected anterior portion of the clypeus, the less projected epistomal angle, and the depressed face around the antennal sockets. The $A$. repanditrostris and $A$. pura species groups are defined as a clade by the absence of tiny setae among long setae on the outer surface of hind tibia and the inflexed apex of T1, both features observed in males. The A. pura group $(\mathrm{PP}=0.62)$ is singly supported by homoplasies and rela- 


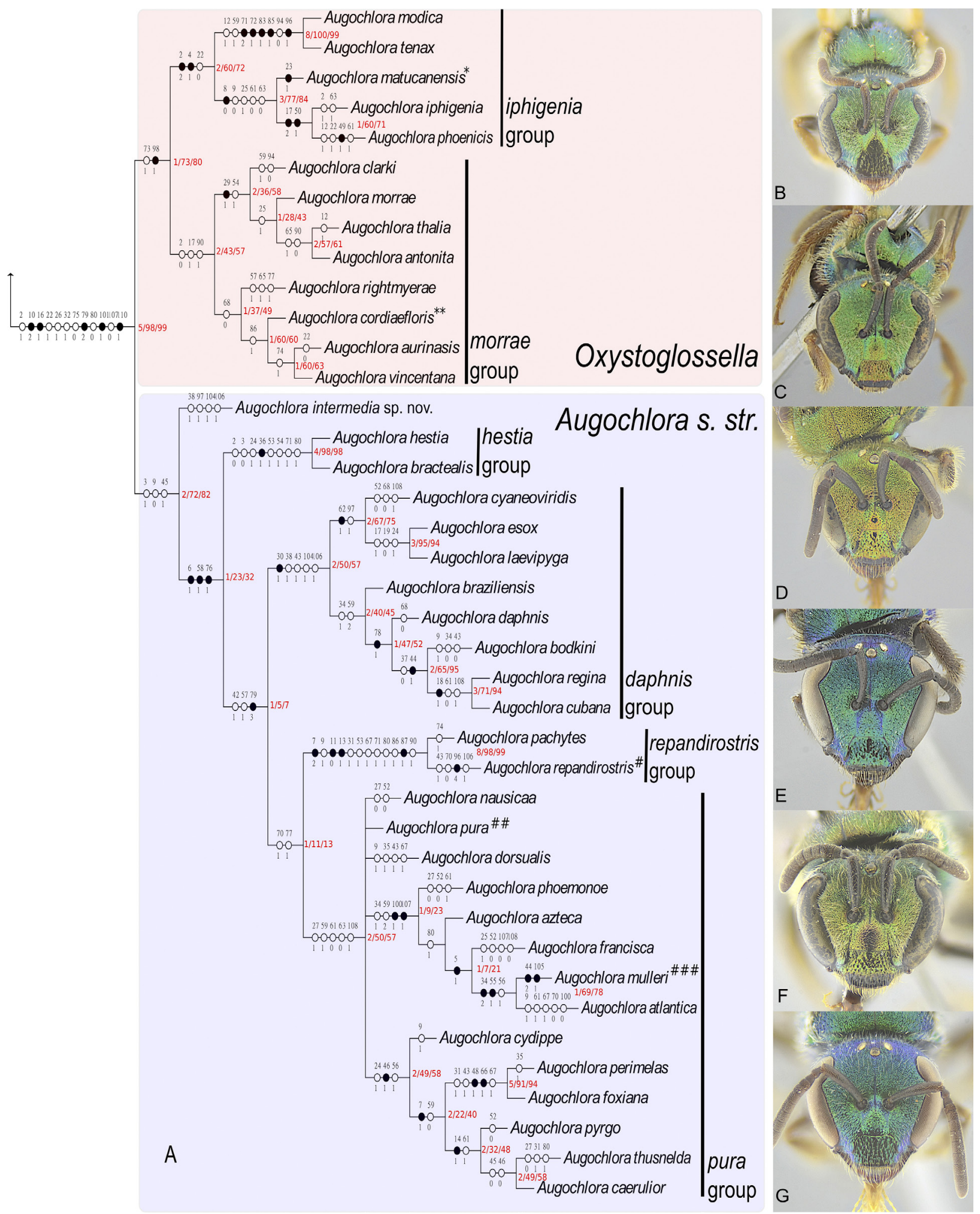

Figure 1. Phylogeny and subgeneric classification of Augochlora Smith. A) Parsimony analysis under implied weighting (k=3, fast optimization). Black and white circles indicate unique and homoplastic changes, respectively. B) Augochlora iphigenia Holmberg, 1886; C) Augochlora morrae Strand, 1910; D) Augochlora hestia Lepeco \& Gonçalves, 2020; E) Augochlora daphnis Smith, 1853; F) Augochlora repandirostris (Vachal, 1911); G) Augochlora pura (Say, 1837). * type of Aethechlora Moure \& Hurd, ** type of Oxystoglossella Eickwort, \# type of Mycterochlora Eickwort, \#\# type of Augochlora Smith, \#\#\# type of Odontochlora Schrottky. Bremer, Bootstrap and Jacknife support values are indicated in red.

tionships among some clades are not clearly identifiable through morphology. While the consensus trees of parsimony analyses resulted in a polytomy at the base (Fig. 1 and Supplementary file 4: Phylogenetic trees, Fig. 3), the
Bayesian analysis with partitioned data indicated $A$. (A.) nausicaa as the sister group with remaining species and A. (A.) pura and A. (A.) dorsualis as related to a clade with $A$. (A.) cydippe. 


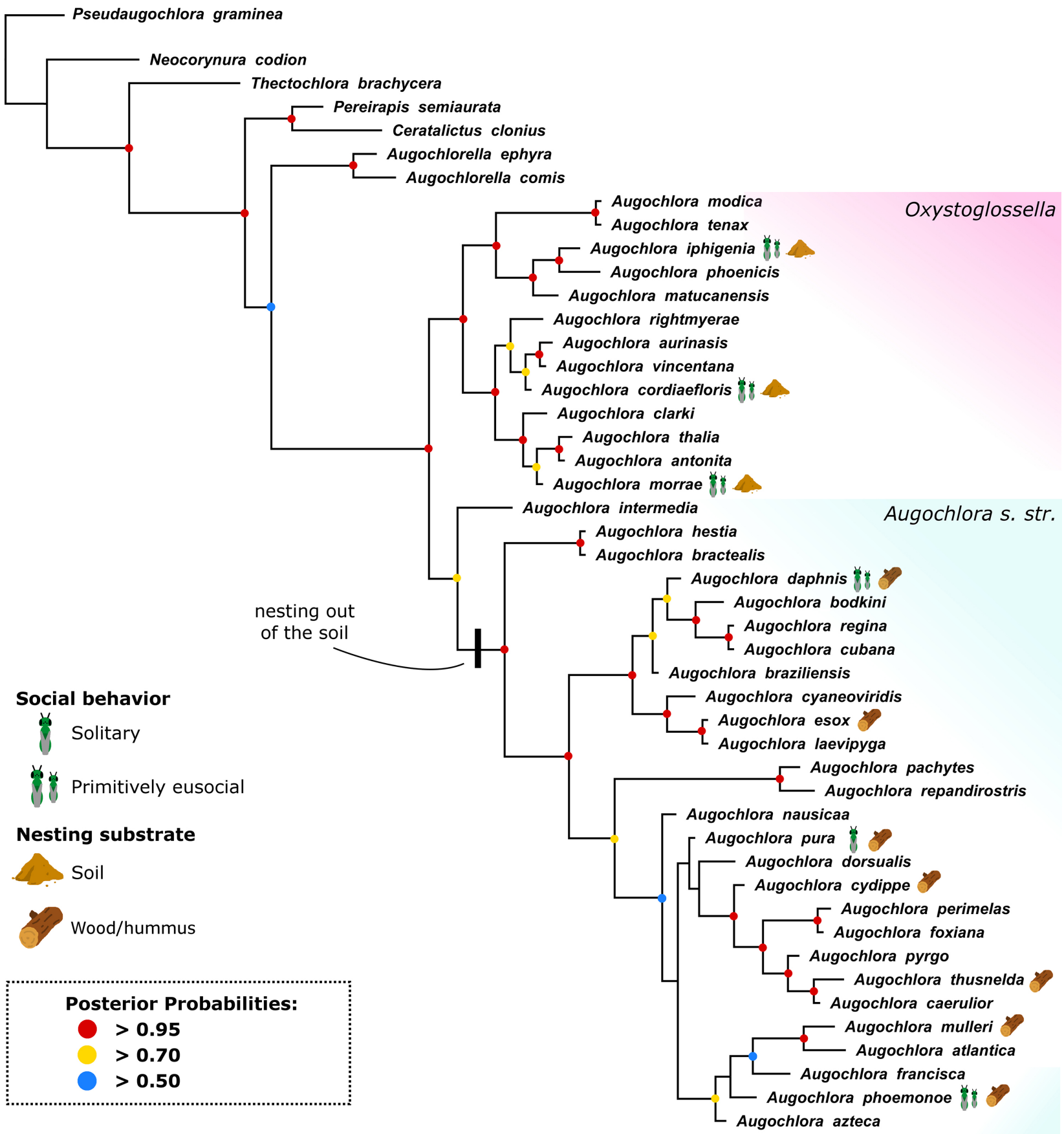

Figure 2. Augochlora Smith majority-rule consensus tree derived from Bayesian analysis of partitioned data. Social behavior and nesting substrate annotated where known. Origin of the behavior of nesting out of the soil was inferred based on morphological clues and on the scattered knowledge about the biology of Augochlora species.

\subsection{Taxonomy}

\subsubsection{Augochlora (Augochlora) intermedia sp. nov.}

http://zoobank.org/NomenclaturalActs/A26D6FDD-D726-4A41-B553-FE5F086B205D

Figure $3 \mathrm{~A}-\mathrm{E}$

Type material. Holotype female (DZUP), "DZUP 1568723 " "LIMA San Bartolomé 26.VII.75\ Coll: R. García" "RG: 537". Paratypes
(DZUP), male "DZUP\568724" "LIMA San Bartolomé 17.VII.75 Coll: R. García" "RG: 537"; female "DZUP $\backslash 568725$ " "Lima (Peru)\ 1.6.1939 leg. Weyrauch" "WKW $\backslash 3773 " ;$ one female and two males pinned together "DZUP \568726" "LIMA, Perú I-1949\P. Aguilar" "FC.64A"; female "DZUP\568727" "LIMA, Perú I-1949\P. Aguilar L." "FC-64A"; female "DZUP $\backslash 568728$ " "No. 606-35\ Hda. Nanipol Jequetepeque 21-XII-1934" "J. Lamas coll."; (RPSP) one female "RPSP $\backslash 15.2461$ " "Peru, Cajamarca, San $\backslash$ Miguel, Florida, 06 51S $\backslash 79$ 07 288W 20.vi.2008\ on Nasa olmosiana".

Diagnosis. Females of the new species can be readily distinguished from most other Augochlora by the distinctly contiguous coarse punctuation, especially on tergal mar- 
ginal area, in combination with the mandible with a small preapical tooth produced far from mandibular apex. In addition, females can be separated from other Augochlora s. str. species by the T5 pseudo-pygidial area covered by scale-like appressed setae (similarly with Oxystoglossella species). From Oxystoglossella species it can be separated by the darkened basal area of labrum and hind coxa angulate on ventral transition between anterior and posterior surfaces. Males are diagnosed by the combination of: F1 as long as F2; hind basitarsus black; metapostnotum shorter than scutellum; T1 with reduced impunctate area medially adjacent to apical dark band (similarly with $O x$ ystoglossella species); T2 with premarginal setae almost reaching apex on sublateral surfaces (similarly with $O x$ ystoglossella species); and outer lobe of gonostylus ventral process with setae shorter than inner lobe.

Description. Holotype Female. Measurements (in mm). Distance between eye notches: 1.8; head length: 2.2; clypeus width: 0.6 ; clypeus length: 0.5 ; clypeoantennal distance: 0.4 ; clypeus ocellar distance: 1.3 ; intertegular distance: 1.6; T1 width: 2.1; T2 width: 2.3 ; body length: 8. — Head. Labrum basal surface black; basal elevation transverse. Mandible mostly black, apex brown; medial portion minimum width about $0.7 \mathrm{x}$ basal width; pre-apical tooth small and rounded, relatively distant from apical tooth apex; distal part of aductor ridge not swollen, but conspicuous in frontal view. Clypeus mostly green with golden reflection, apical black band as long as OD; mostly densely punctate $(\mathrm{I}<\mathrm{PD})$, punctures large, medially with an impunctate longitudinal path, imbricate among punctures. Supraclypeal area green with golden reflection; mostly contiguously punctate, sparser towards clypeus, imbricate among punctures. Lower paraocular area green with golden reflection; contiguously punctate; long setae (3 OD) intermixed with tiny setae. Antennae: mostly black, flagellum ventrally brownish. Frons green with golden reflection; contiguously punctate; not protuberant above antennal sockets. Preoccipital carina not enlarged near post-gena. Gena with golden reflection. Post-gena darkened; microreticulate, some scattered weak punctures; setae length $<3$ OD. Hypostomal carina not projected anteriorly. - Mesosoma. Pronotum dorsolateral angle obtuse, not strongly projected. Fore leg: entirely dark brown, longer setae length $=3$ OD. Mesoscutum green; mostly contiguously punctate, anterior portion crowded punctate to imbricate; with long dark setae (2 OD) intermixed with tiny setae. Scutellum green; without strong medial furrow; contiguously punctate; with long dark setae (3 OD) intermixed with tiny setae. Mesepisternum green with golden reflection; mostly contiguously punctate, anterior portion crowded punctate; with long setae (3 OD) intermixed with tiny setae. Mid leg: entirely dark brown, longer setae length $=3 \mathrm{OD}$; trochanter ventral margin straight; femur posterior surface flat; mesofemoral brush yellowish. Tegula dark brown. Metanotum longer setae length $=2$ OD. Metepisternum green; contiguously punctate, becoming crowded to rugose above metapleural pit. Hind leg: mostly dark brown, except for green anterior surface of coxa; transition between anterior and posterior surfaces of coxa ventrally making a strong angulation; without black setae on tibia and basitarsus. Metapostnotum green; as long as $0.7 \mathrm{x}$ scutellum length; with almost straight radiating carinae, slightly imbricate in between. Propodeum green with golden reflection; with long setae (3 OD) intermixed with tiny setae; posterior surface mostly imbricate with some scattered distinct punctures, lateral surfaces crowded to contiguously punctate near metepisternum. - Metasoma. T1 anterior surface densely punctate (I = 0.5 PD), loosely imbricate among punctures; with long setae (2 OD) intermixed with tiny decumbent setae. T1 dorsal surface contiguously punctate, mostly with small and deep punctures, larger punctures on lateral surfaces; mostly green, apical black band shorter than OD; apex not inflexed. T2 green; densely punctate ( $\mathrm{I}=0.5 \mathrm{PD})$, mostly with small and deep punctures, smooth in between, larger punctures on lateral surfaces; marginal zone with punctate portion $4 x$ longer than apical brown band on sublateral surfaces. T3 green; densely punctate ( $=0.5 \mathrm{PD})$, loosely imbricate in between; apex of tiny setae surpassing apex of T3 sublaterally. T4 green; weakly punctate, imbricate in between. T5 light brown; pseudo-pygidial area medially without scale-like decumbent setae, colliculate. Pygidial plate dark brown, apex rounded. S1 brown; very slightly prominent medially, without distinct projection; long setae $(<5$ OD) medially, margin with tiny decumbent setae. S2 brown; sparsely punctate, microreticulate in between; long setae (<4 OD) on posterior half. S3-5 as S2. S6 dark brown.

Description. Paratype male. Measurements (in $\mathbf{m m}$ ). Distance between eye notches: 1.6; head length: 2.1; clypeus width: 0.6 ; clypeus length: 0.5 ; clypeoantennal distance: 0.4 ; clypeocellar distance: 1.2 ; intertegular distance: 1.3; T1 width: 1.4; T2 width: 1.5; scape length: 0.6; body length: 9. — Head. Labrum basal surface light yellowish. Mandible dark brown. Clypeus mostly green with golden reflection, apex yellowish, apical border exposed, yellowish; densely punctate, I $=0.5 \mathrm{PD}$, punctures large and shallow, loosely imbricate in between. Supraclypeal area green with golden reflection; mostly contiguously punctate, sparser towards clypeus, loosely imbricate among punctures. Paraocular area green with golden reflection; densely punctate, I $<0.5 \mathrm{PD}$, smooth in between; long setae (2 OD) and short setae intermixed. Antennae: mostly black, flagellum ventrally yellowish; F1 as long as F2; F3 as long as wide; remaining flagellomeres progressively longer. Frons mostly green, with golden and blue iridescences intermixed; mostly contiguously punctate, crowded punctate near mid ocellus. Gena green with golden reflection. Post-gena darkened, with golden reflections; loosely imbricate, some scattered weak punctures; sparse long setae $(<4$ OD). - Mesosoma. Pronotum dorsolateral angle obtuse, not strongly projected. Fore leg: mostly brown, except for green coxae anteriorly and femur outer surface; trochanter and femur not strongly swollen. Mesoscutum green; densely punctate $(\mathrm{I}=0.5 \mathrm{PD})$, mostly loosely imbricate in between, anteriorly microrreticulate among punctures; with long 


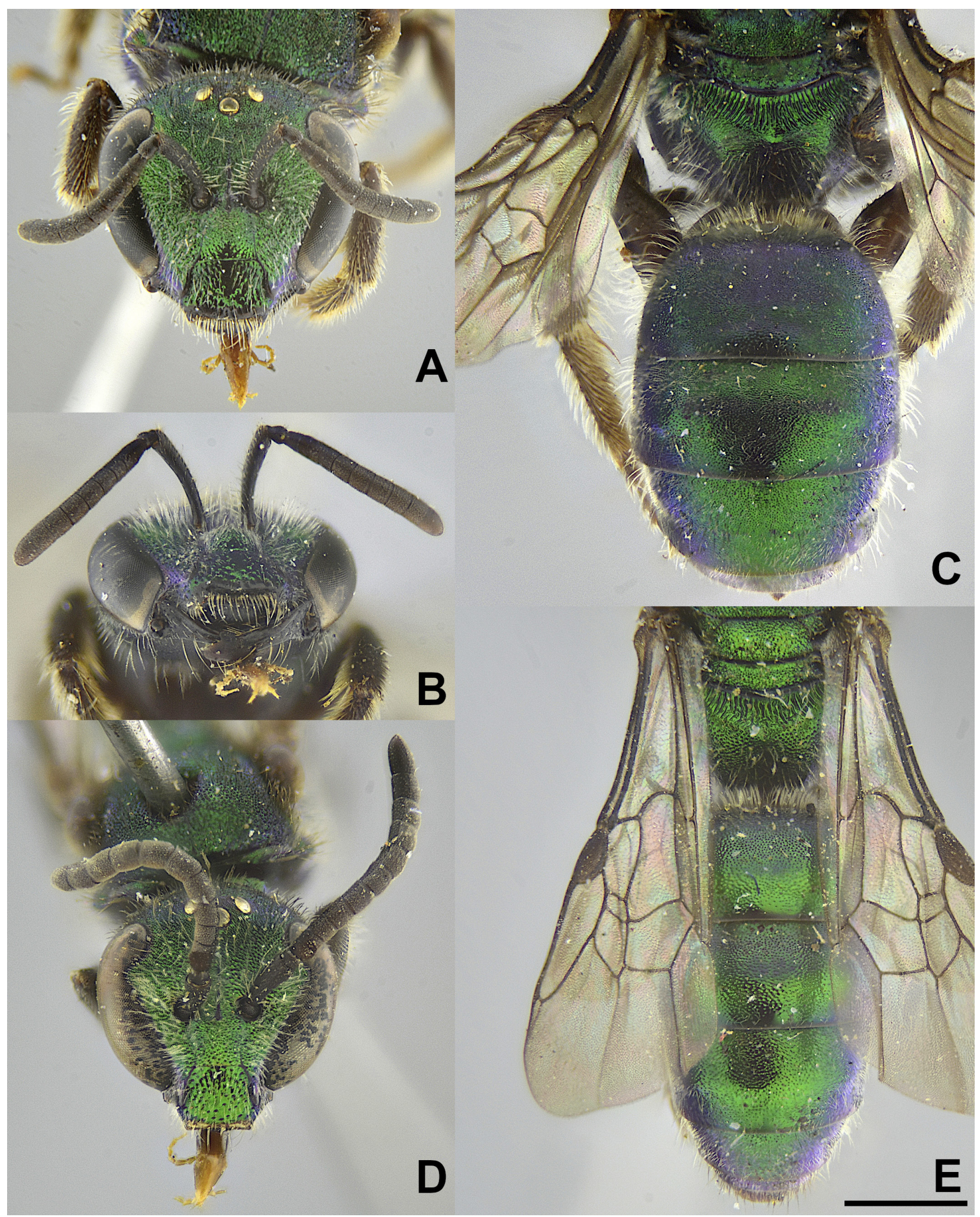

Figure 3. Augochlora intermedia sp. nov. Female (holotype): A) frontal view of head, B) anterior view of head, C) dorsal view of mesosoma and metasoma; male (paratype): D) frontal view of head; E) dorsal view of mesosoma and metasoma. Scale bar: $1.0 \mathrm{~mm}$, all at same scale.

dark setae (2 OD) intermixed with tiny setae. Scutellum green with golden reflection; medial furrow inconspicuous; densely punctate $(\mathrm{I}<0.5 \mathrm{PD})$, punctures coarse; with long dark setae (2 OD) intermixed with tiny setae. Mesepisternum green with golden reflection; mostly densely punctate $(\mathrm{I}<0.5 \mathrm{PD})$, anterior portion crowded punctate; with long setae (3 OD) intermixed with tiny setae. Mid leg: coxa mostly dark brown, except for green femur posterior surface; longer setae length $=2 \mathrm{OD}$; femur not strongly swollen. Tegula dark brown. Metanotum longer setae length $=2$ OD. Metepisternum green with golden reflection; contiguously punctate, becoming crowded to 
rugose above metapleural pit. Hind leg: coxa mostly dark brown, except for coxae posterior surface green and trochanter and femur with faint blusih iridescences; femur outer surface with tiny setae among longer setae; basitarsus about 6x longer than maximum width, parallel sided. Metapostnotum green; about as long as metapostnotum; gently depressed transversally; mostly with sinuous radiating carinae, posteriorly rugose. Propodeum densely punctate $(\mathrm{I}<0.5 \mathrm{PD})$, loosely imbricate in between; with long setae (2 OD) intermixed with tiny setae. - Metasoma. T1 anterior surface sparsely punctate, punctures deep, loosely imbricate in between; only with long setae (2 OD). T1 dorsal surface mostly contiguously punctate, becoming densely punctate $(\mathrm{I}=0.5 \mathrm{PD}$ ) towards apex, coarser punctures on lateral surfaces; mostly green with golden reflection, apical black band $=0.5 \mathrm{OD}$; apex not inflexed. T2 mostly green with golden reflection; mostly contiguously punctate, becoming sparser towards apex; marginal zone with punctate portion $3 \mathrm{x}$ longer than apical brown band on sublateral surfaces; T3 mostly green with golden reflection, apex darkened; punctate (I = PD), smooth in between. T4 mostly green with golden reflection, apex darkened; punctate $(I=P D)$, smooth in between. T5 mostly green with golden reflection, apex darkened; sparsely punctate, punctures weak, smooth in between. T6 brown, with faint green reflection; weakly punctate. T7 light brown. S1 brown; with a slight longitudinal sulcus medially. long setae $(<2$ OD) medially, margin with tiny decumbent setae. S2 mostly brown, apical portion yellowish; sparsely punctate, microreticulate in between; with short setae (= OD), more abundant near apex. S3-4 as S2. S5 apical portion not depressed; covered with tiny setaccurrihout medial glabrous path. S6 brown; with tiny setae, more abundant near apex. S7 lateral apodemes longer than half S8 width. S8 anterior projection more than four times longer than apical width; posterior margin acuminate. Genitalia: gonobase 2.0 times wider than long; gonobase ventral arms slightly curved on apex. Gonocoxite about 2.0 times longer than wide. Gonostylus, dorsal surface glabrous. Ventral process of gonostylus: inner lobe slender; with long and short setae intermixed; outer lobe with short setae with length $=0.7$ inner lobe size. Gonapophysis ventral prong well produced and broad; dorsal bridge margin weakly projected; ventral bridge absent; apodeme narrow and strongly hooked.

Etymology. Nominative feminine of intermedius, meaning in the middle, a reference to intermixed features of Augochlora subgenera found in this species.

Distribution. Specimens were collected in Lima and La Libertad departments (Peru), western of Andean Mountains.

Comments. The holotype and a couple of paratypes have bluish reflections while remaining specimens are mostly green with few reddish reflections, besides this color variation the specimens have very similar body ornamentation and imperceptible differences in size.

\subsubsection{Augochlora (Augochlora) bractealis (Vachal, 1904), new combination}

Halictus bractealis Vachal, 1904. Holotype male (MNHP) from Peru, 'Villanota' [probably lapsus for Vilcanota, in Cuzco, Peru]. Examined through photographs.

Halictus pyrrhias Vachal, 1911. Lectotype female (MNHP) from Peru, Marcapata. Examined through photographs. New synonym.

Comments. Moure and Hurd (1987) designated the lectotype for Halictus pyrrhias and considered both names under Oxystoglossella, a decision followed by Moure (2007). We examined the photographs of the types from both names (Muséum d'Histoire Naturelle, Paris, France) and the specimens belong to the $A$. hestia species group in Augochlora s. str. We also consider that the male and female are the same species proposing the synonymy for these names. As discussed herein, this species superficially resembles Oxystoglossella and shares labral modifications with that subgenus, what justified Moure and Hurd's (1987) generic assignment.

\subsubsection{Electraugochlora Engel, new status}

Electraugochlora Engel, 2000. Type species: Augochlora (Electraugochlora) leptoloba Engel, 2000 by original designation. Not examined.

Comments. We made some efforts to include this species in our analysis based on the original description, but the results were very unstable, probably due to the large amount of missing data. According to the original description and a revised phylogeny of Augochlorini (Gonçalves et al. in press), A. leptoloba could be a sister group with all other Augochlora. However, the uncertainty on several morphological attributes of this species and the lack of the acute angle of epistomal sulcus, a distinctive feature of Augochlora, are indicative for us to consider Electraugochlora as a separate genus.

\section{Discussion}

\subsection{Phylogeny and taxonomy of Augochlora}

Herein we analyzed a morphological matrix for Augochlora under two different approaches - parsimony criterion and Bayesian inference. The genus and both extant subgenera were recovered as monophyletic, with relatively high support values on all analyses. Within the genus, both approaches provided very similar topologies, allowing us to consistently identify major lineages. Partitioning using characters' level of homoplasy resulted in trees more alike those generated by implied weighting parsimony, which is expected since both approaches do not treat characters as equally influential for topology estima- 
tion. This kind of approach yielded trees with outgroup relationships identical to those recovered by molecular and total-evidence analyses (Gonçalves 2016; Gonçalves et al. in press). The use of parsimony is widespread for morphological datasets, probably as a reflex of tradition and simplicity. On the other hand, the use of model-based approaches for phylogeny estimation of discrete morphological data is increasing and revealing many advantages over other methods (see Wright and Hillis 2014' O'Reilly et al. 2016). We understand that the concomitant use of parsimony and Bayesian approaches helps to better explore available information.

One of our main goals was to evaluate the valid subgeneric classification (sensu Engel 2000, Michener 2007; Moure 2007). As both extant subgenera were recovered as monophyletic, their use should be maintained for stability. To achieve this, a species placed in Oxystoglossella in the current classification (Moure and Hurd 1987; Moure 2007), A. bractealis should be transferred to Augochlora s. str. This species superficially resembles Oxystoglossella, and also have some labral modifications shared with that subgenus, but it belongs to the $A$. hestia species group in Augochlora s. str. (synapomorphies supporting a close relationship between $A$. (A.) bractealis and $A$. (A.) hestia are shown in Fig. 1). Our results support the use of Aethechlora as a separate subgenus for A. iphigenia species group, but this can unecessarely inflate the taxonomy of the group and besides the original description by Moure and Hurd (1987) no other author considered the validity of this subgenus. We also favor maintaining Augochlora s. str. as a subgenus with no further modifications, since the use of Mycterochlora as a separate subgenus for the $A$. repandirostris species group would unnecessarily require raising three new subgenera. The unique $A$. (A.) intermedia sp. nov. is remarkable in having mandibles and pseudo-pygidial area modifications characteristic of Oxystoglossella while its genital capsule is typical from Augochlora s. str. Despite the monophyly of the subgenera, we found that characters frequently used to separate them (Eickwort 1969; Engel 2000) are variable along the phylogeny. The single exception is the length of the setae on the outer lobe of gonostylus - the long setae are a synapomorphy of Oxystoglossella, while Augochlora s. str. have short setae, as in the outgroup.

The large and produced preapical tooth was considered as a characteristic feature of Augochlora s. str. females (Eickwort 1969; Engel 2000), and besides $A$. (A.) intermedia sp. nov., the remaining species of the subgenus have this modification. Although mandibular teeth can bear some degree of wear depending on the specimens, it is clear that some species have a broadly rounded preapical tooth, less detached from the upper margin of the rutellum. The mandibles also have distinct modifications in other clades. In the A. iphigenia species group they are elongated with a broad apical tooth, a condition taken to the extreme in some macrocephalic forms, as in $A$. (O.) matucanensis and $A$. (O.) phoenicis. In some species of the $A$. pura group, there is a strong constriction before the distal part of aductor ridge in frontal view, as was noted in $A$. (A.) atlantica, $A$. (A.) francisca and $A$.
(A.) mulleri, also occurring in A. (A.) genalis Lepeco \& Gonçalves (Lepeco and Gonçalves 2020a: Fig. 1). The shape of the elevation on the basal area of the labrum was also considered diagnostic of the subgenera, with the transverse elevation being typical for Augochlora s. str. and an orbicular shape for Oxystoglossela (Engel 2000). However, the shape is quite variable among species. The orbicular form is found only in the A. morrae group from Oxystoglossella and also on the A. hestia group. A. (A.) iphigenia also has a transverse elevation as interpreted by Gonçalves (2019), and its allied species have a slight elevation, without a well-defined shape, as discussed for $A$. (O.) modica and $A$. (O.) tenax by Lepeco and Gonçalves (2020b).

We noted that the pseudo-pygidial area on the fifth tergum is a key element in the systematics of Augochlora, but it has been described in different ways by previous authors. Eickwort (1969) considered that species in $\mathrm{Au}$ gochlora s. str. bear scale-like setae in the pseudo-pygidial area of T5, while Oxystoglossella lack these setae. This character was not mentioned by Engel (2000), but posteriorly Dalmazzo and Roig-Alsina (2011) considered that species of Oxystoglossella bear setae-like spicules, while Augochlora s. str. bear globose spicules (see Figures 11 and 12 of the latter work). Lepeco and Gonçalves (2020a) suggested that the structures found in Augochlora s. str. are simply the colliculate integument exposed due to the absence of scale-like setae found in Oxystoglossella. All species of Oxystoglossella and the outgroup bear appressed setae on the pseudo-pygidial area, somewhat resembling scales, while most Augochlora s. str. lack these setae and have a more sclerotinized irregular surface on each side of the medial cleft of T5. This irregular surface is formed by many tiny protuberances, clearly shown by Dalmazzo and Roig-Alsina (2011: Fig. 12), that are not similar with setae or scales. We maintain the interpretation of Lepeco and Gonçalves (2020a), adding the indication that the setae found in the medial area of T5 in Oxystoglossella are appressed, to avoid confusion with the terms coined by Eickwort (1969) and Dalmazzo and Roig-Alsina (2011). The presently described $A$. (A.) intermedia sp. nov. is the single Augochlora s. str. to bear appressed scale-like setae on the pseudo-pygidial area, although the coverage is sparser than observed in Oxystoglossella, maybe representing an intermediate state.

\subsection{Implications for biogeography}

Augochlora is a widespread genus in the Western Hemisphere, but much of its diversity and distribution patterns are largely unknown. In the case of the revised fauna from Southern South America (Lepeco and Gonçalves 2020a), it is clear that species exhibit different ranges and habitat tolerances, with some of them occurring in areas strictly covered by rainforests and others also reaching regions of open vegetation. An important observation derived here is that the main lineages, the species groups, have a widespread distribution on western hemisphere. Our taxon sampling is inadequate for a formal biogeographic re- 
construction, as we did not sample regions equally within species groups, leaving many distributional gaps in our data. In addition, the diversity of some regions, such as Mesoamerica and Amazonia, is not fully known, leaving an obstacle for any phylogenetic and biogeographic exploration. Therefore, in light of our knowledge on the subject, we bring some insights also considering species not represented in our phylogeny.

Oxystoglossella is less speciose in comparison to $\mathrm{Au}$ gochlora s. str., allowing us to identify some distribution patterns based on the studied species. The A. iphigenia species group is restricted to South America. Within this group, A. (O.) modica and $A$. (O.) tenax are recovered as sister species in our results, being typical from the Caatinga in Northeastern Brazil, a region characterized by dry conditions and high temperatures (Lepeco and Gonçalves 2020b). Augochlora (O.) mendax Lepeco and Gonçalves, 2020 is very similar to $A$. (O.) modica, and is found throughout the Cerrado formation, in central Brazil. A fourth species is known to us only from the Serra do Cipó locality, in Minas Gerais, Brazil, characterized by dry conditions. It seems clear that these four species presumably form a monophyletic group well-adapted to Brazilian open vegetational formations, being the single group bearing this characteristic within the genus. On the other hand, the clade composed of $A$. (O.) iphigenia, $A$. (O.) phoenicis and A. (O.) matucanensis is more heterogeneous. A. (O.) iphigenia is abundant from central Brazil to the Argentine Pampas, while A. (O.) phoenicis is found only within Western Amazonia, and $A$. (O.) matucanensis is the single species in the subgenus found in the Pacific side of the Andean mountain range in Peru. The $A$. morrae species group is mostly composed of commonly collected species, distributed throughout the almost entire range of the subgenus, with $A$. (O.) vincentana occurring at Caribbean islands (Moure 2012). Another species, not studied here, was described for Haiti: A. (O.) haitiensis (Vachal, 1911). Finally, a few species of Oxystoglossella occur in Central America, and at least three species occur in Mexico, with $A$. (O.) aurifera Cockerell, 1897 also recorded for the USA (Ascher and Pickering 2021).

Within Augochlora s. str., the A. daphnis and A. pura species groups are the more widespread, with the later also being the more speciose and morphologically diverse. Representatives of both groups are found in the USA, with $A$. (A.) pura reaching Canada and $A$. (A.) nigrocyanea Cockerell, 1897, a species undoubtedly belonging to the $A$. daphnis group, reaching southern USA (Sandhouse 1937; Moure 2012). Our results indicate that the occupation of the Nearctic region occurred within few derived taxa, disfavoring a scenario where Augochlora originated in North America. Interestingly, both species groups are found in the southernmost locality where Augochlora were ever collected - the Neuquén Province in Argentina - since A. (A.) australis Lepeco and Gonçalves, 2020 and A. (A.) hirsuta Lepeco and Gonçalves, 2020 are probably related to A. pura and A. daphnis species groups respectively. All Augochlora s. str. known to us from the Caribbean islands seem to be related to the $A$. daphnis species group, and, according to our results, the occupation of
Caribbean islands occurred at least three times within derived taxa of the genus. An early diversification of Augochlora in the Caribbean islands cannot be discarded if we consider that E. leptoloba is the sister group with all other Augochlora (Gonçalves et al. in press). From A. daphnis group came the only species recorded on Fernando de Noronha archipelago (545 km from Brazilian coast), Augochlora laevipyga is related to Augochlora esox.

The $A$. repandirostris species group is more abundant and diverse in the Amazon rainforest, but can also be found in the Panamanian Forest (e.g., A. (A.) isthmii Schwarz, 1934), and in the Atlantic Forest, (A. $(A$.) helena Lepeco and Gonçalves, 2020 and an undescribed species from Espírito Santo). The A. hestia species group has a similar distribution with two species from Amazonian Forest and one species widespread in the Atlantic Forest known to date. Species from both groups seems to be restricted to rainforests, with no representative being ever recorded in the open formations of South America. They also were not collected in the Caribbean.

The western coast of Peru appears to be an important region for the biogeography of the genus, with two species occurring there $-A$. (A.) intermedia sp. nov. and A. (O.) matucanensis. Both species are morphologically unique, and the former is the single representative of a lineage sister to all other Augochlora s. str. Nevertheless, the diversity of Augochlora in Peru, western to the Andean mountain range, seems to be low. The original label of A. (O.) matucanensis indicates that these bees were collected at Andean foothills, where vegetational conditions may diverge from that explored by most of Augochlora species Another case to be addressed is $A$. (A.) notialis (Vachal, 1904), known only from the male holotype, labeled from Chile. Unfortunately, we did not examine the holotype and, according to Moure and Hurd (1987), it was probably mislabeled.

In summary we understand that the first evolutionary and biogeographic events of extant Augochlora lineages took place in South America. This seems to be evident by the diversity of Oxystoglossella, as a few groups with distinctive morphologies are restricted to South America. In the case of Augochlora s. str., two of its early branching lineages are endemic to South America (i.e., A. intermedia sp. nov. and $A$. hestia species group). Nevertheless, a refined elucidation of the biogeographic history of Augochlora can only be achieved with better understanding of its taxonomy and phylogeny.

\subsection{The social behavior of Augochlora}

Despite direct observation, the social behavior can be also positively inferred from intraspecific polymorphisms. Augochlora (O.) iphigenia, A. (O.) matucanensis and $A$. (O.) phoenicis are remarkable for the existence of females with distinct head enlargement, along with expansion of the apical portion of the mandible and projection of the hypostomal carina. These characteristics were also documented in $A$. (O.) empusa Engel, Hinojosa-Díaz and Bennett, 2012, which is probably a junior synonym of 
A. phoenicis. Morphological polymorphisms of this sort are often linked to social interactions within the nest, as the large foundress females of primitively eusocial bees physically subjugate their subordinate daughters (Pabalan et al. 2000; Packer et al. 2003). Allometric growth of head structures in females is also present in species of the $A$. daphnis group (including the facultatively eusocial $A$. daphnis) and in A. (A.) genalis Lepeco and Gonçalves, 2020, a putative member of the $A$. pura species group (Lepeco and Gonçalves 2018; Lepeco and Gonçalves 2020a). It is unclear whether such modifications are invariably related to eusociality, even so, conspicuous cephalic polymorphism seems to have evolved at least three times independently in the genus.

Michener (1990) pointed out that solitary behavior in Augochlora s. str. represented a reversal from eusociality, since Oxystoglossella and the related genera are primitively eusocial (Eickwort 1969; see also Danforth and Eickwort 1997). A. (A.) pura is a well-known solitary species, and no signals of eusociality were found in $A$. (A.) hallinani Michener, 1954; A. (A.) sidaefoliae Cockerell, 1913; and $A$. (A.) smaragdina Friese, 1916 (Stockhammer 1966; Eickwort and Eickwort 1973). It is difficult to conclude whether these species are indeed solitary, due to the low number of nests observed. Given the presence of eusociality in $A$. (A.) isthmii, a member of the repandirostris species group, and in $A$. (A.) daphnis and $A$. (A.) phoemonoe (Dalmazzo and Roig-Alsina $2012,2015,2018 \mathrm{a}, 2018 \mathrm{~b}$ ), our results point to the presence of primitively eusocial species in at least three of the five Augochlora s. str. species groups, indicating that the exclusive solitary behavior of $A$. (A.) pura can be a reversion case.

Eusociality has been lost many times in eusocial Halictinae lineages (Danforth 2002; Gibbs 2012). Unlike in fixed-caste eusocial taxa (e.g., Apini, Meliponini), reversal to solitary behavior does not represent a large evolutionary obstacle for the Halictinae. Since all totipotent-caste eusocial bees pass through a solitary phase during the year (i.e., nest construction and provisioning before the first brood emerging) shift to solitary behavior would be acquired by simply changing from a multivoltine to univoltine cycle, where only reproductive brood is raised (Gibbs 2012; see also Almeida and Porto 2014). In fact, eusociality is facultative in many Halictinae species, being determined at the transcriptional level and influenced by climatic conditions, with females behaving as solitary in colder regions (Sakagami and Munakata 1972; Eickwort et al. 1996; Kapheim et al. 2020). Another important factor is resource limitation, species that nest in wood often have to cope with substrates with different sizes, shapes and diggability, which probably limit colony expansion (Dalmazzo and Roig-Alsina 2015).

Among Augochlora, facultative behavior can be suggested for $A$. (A.) daphnis, since individual nests were found both with a single female or with many females dividing activities (Dalmazzo and Roig-Alsina 2012). This is also the case of $A$. (A.) isthmii (Wcislo et al. 2003) and probably for the remaining Augochlora s. str.. Other kinds of social organization, such as communal nesting, may be common within the genus, as it is the case for Halictinae (Michener 2007). We suggest that eusociality is a plastic characteristic in the genus, perhaps with multiple gains and losses along its evolution. Additionally, the eusocial behavior in Augochlora is probably facultative as a rule. Nevertheless, the evolutionary history of eusocial behavior will be only completely understood with nest observations and detailed records.

\subsection{Nesting biology insights}

Modified mandibles and absence of appressed scale-like setae on pseudo-pygidial area are found in primarily wood-nesting augochlorines. The studied nesting species of Megalopta Smith and allied genera (Megaloptosyne Engel and Xenochlora Engel, Brooks and Yanega) nest in decaying wood, and their females have strong mandibles with supplementary teeth on the inner surface (Michener and Fraser 1978; Santos et al. 2010) and colliculate pseudo-pygidial area, without appressed setae (see Engel 2000: Fig. 59). The same T5 modification and developed preapical tooth can be found in some species of Neocorynura Schrottky which nest in wood (Eickwort 1969; Brosi et al. 2006), but in this case a phylogeny to trace the origin of these traits is lacking. All species of Augochlora s. str. studied so far nest out of the soil (Table 1), and, using the mentioned morphological clues, we suggest that this behavior evolved in the common ancestor of the A. hestia, A. daphnis, A. repandirostris and A. pura species groups. Although the new species, A. intermedia sp. nov., is more related to Augochlora s. str. species, it has mandibles typical of soil-nesting species and sparse scale-like setae on the pseudo-pygidial area. Alternatively, the new species may be a facultative wood-nester, as is the case of $A$. ( $A$.) esox, recorded nesting on bromeliad humus (Zillikens et al. 2001) but also found nesting in wood (G. A. R. Melo, personal communication). Nevertheless, Augochlora s. str. may not be strictly dependent on a single type of nesting substrate, a conclusion supported also by laboratory rearing of $A$. (A.) pura in soil (Barrows 1973).

In regard to nest architecture, bees exhibit a certain level of plasticity, adapting the organization of structures according to substrate conditions (Eickwort and Sakagami 1979). Nests with clusters of cells supported by earthen pillars within a hollow cavity are the commonest among Augochlorini, probably representing a plesiomorphy for the Augochlora group of genera (Danforth and Eickwort 1997; Engel 2000; Wcislo et al. 2003; Coelho 2004). These clusters facilitate the isolation of cells from the surrounding soil by means of a drainage cavity, protecting the provisions and brood from excessive moisture (Sakagami and Michener 1962; Eickwort and Sakagami 1979; Wcislo et al. 2003). Clusters surrounded by cavities are present in nests of $A$. (A.) daphnis within soft wood, but were not found in trunks with harder wood (Dalmazzo and Roig-Alsina 2012). In the other few Augochlora nests studied, clusters are either present or not, showing no consistent phylogenetic pattern. On the other hand, all 
Table 1. Nesting substrate and social behavior of Augochlora Smith species.

\begin{tabular}{|c|c|c|c|}
\hline Species & Nesting substrate & Social behavior & References \\
\hline A. (A.) alexanderi Engel, 2003 & wood & - & Wcislo et al. (2003) \\
\hline A. (A.) cydippe (Schrottky, 1910) & wood & - & Lepeco and Gonçalves (2020a) \\
\hline A. (A.) daphnis Smith, 1853 & wood & Primitively eusocial & $\begin{array}{l}\text { Dalmazzo and Roig-Alsina (2012,2018b); Lepeco and } \\
\text { Gonçalves (2018) }\end{array}$ \\
\hline A. (A.) esox (Vachal, 1911) & wood/hummus & - & Zillikens et al. (2001); unpublished data \\
\hline A. (A.) hallinani Michener, 1954 & wood & Solitary?* & Eickwort and Eickwort (1973) \\
\hline A. (A.) isthmii Schwarz, 1934 & wood & Primitively eusocial & Wcislo et al. (2003) \\
\hline A. (A.) mulleri Cockerell, 1900 & wood & - & Sakagami and Moure (1967) \\
\hline A. (A.) phoemonoe (Schrottky, 1909) & wood & Primitively eusocial & Dalmazzo and Roig-Alsina (2018a) \\
\hline A. (A.) pura (Say, 1837) & wood** & Solitary & Stockhammer (1966) \\
\hline A. (A.) sidaefoliae Cockerell, 1913 & wood & Solitary? & Eickwort and Eickwort (1973) \\
\hline A. (A.) smaragdina Friese, 1916 & wood & Solitary? & Eickwort and Eickwort (1973) \\
\hline A. (A.) thusnelda (Schrottky, 1909) & wood & - & Lepeco and Gonçalves (2020a) \\
\hline A. (O.) cordiaefloris Cockerell, 1907 & soil & Primitively eusocial & Eickwort and Eickwort (1972) \\
\hline A. (O.) iphigenia Holmberg, 1886 & soil & Primitively eusocial & $\begin{array}{l}\text { Michener and Lange (1958); Sakagami and Moure } \\
(1965)\end{array}$ \\
\hline A. (O.) morrae Strand, 1910 & soil & Primitively eusocial? & Michener and Lange (1958) \\
\hline A. (O.) nominata Michener, 1954 & soil & Primitively eusocial & Eickwort and Eickwort (1972) \\
\hline \multicolumn{4}{|c|}{$\begin{array}{l}\text { * Some species were studied based on a few nests and/or localities and conclusions are based on behavioral clues rather than on observation of } \\
\text { the entire life cycles, making it difficult to determine if sociality is actually absent or occasionally not observed. }\end{array}$} \\
\hline
\end{tabular}

Oxystoglossella studied so far do not construct cells in clusters (Eickwort and Sakagami 1979), suggesting that their absence is not necessarily linked to wood-nesting. Nevertheless, it is not known whether the absence of clusters and/or hollow cavities surrounding cells in nests of Augochlora s. str. is related to the better drainage proportioned by wood, as suggested by Wcislo et al. (2003), or due to heterogeneity of wood material in relation to soil, where conditions allow females to express their full construction capabilities (Dalmazzo and Roig-Alsina 2012). In the latter case, environmental conditions have a major role in defining architecture in relation to phylogenetic relationships.

Decaying wood has the disadvantage of being less abundant in comparison to suitable soil, but, on the other hand, it is more difficult to become soaked during periods of rainfall and retains humidity in dry periods (Stockhammer 1966). Regarding social behavior, nesting above ground did not limit Augochlora s. str. to the solitary lifestyle (Dalmazzo and Roig-Alsina 2012, 2015, 2018a, 2018b). Examining other augochlorine wood nesters, Megalopta and allied genera can be primitively eusocial (Kapheim et al. 2020), but for Neocoynura this behavior was not yet published (Brosi et al. 2006) and there are no morphological clues such as female polymorphisms. Michener (1990) suggested that the scarcity of suitable plant material, in contrast to soil, triggered the reversion to solitary behavior, as natural enemies in forest environments were less successful and, therefore, disadvantages of eusociality outweighed the advantages. This argument, if valid, is restricted to temperate species $A$. (A.) pura so far.

As is common for bees, Augochlora are parasitized by conopid flies and mutillids (Michener and Lange 1958).
The single putative cleptoparasite bees to attack nests of the genus are Temnosoma Smith: females of an unidentified species were already seen flying around and found within nests of $A$. (A.) esox (Silveira et al. 2002). Eickwort (1969) suggested that Temnosoma were cleptoparasites of eusocial species, given their distinctively coarse integuments. The association of Temnosoma with Augochlora is supported by the distribution of both genera - these are the only augochlorine genera occurring simultaneously at USA, Chile and the antilles, besides most of the Neotropical region (Eickwort 1969; Michener 2007; Moure 2012). If Temnosoma did not parasitise other groups, this association may represent an adaptation to host-seeking in an unusual substrate, i.e., decaying wood. A similar trend is found on the cleptoparasitic species of the wood nester Megalopta (Michener 2007). Considereing this hypothesis, the utilization of decaying wood for nesting may have facilitated the origination of cleptoparasitic lineages within the tribe, with less competitors, since other soil nesting genera (e.g., Augochlorella) are usually attacked by the widespread genus Sphecodes Latreille (Ordway 1965).

\section{Acknowledgements}

We are thankful to Gabriel A. R. Melo for sharing his own observations on Augochlora nesting biology and material from nests. The undergraduate scholarship for the first author was granted by Universidade Federal do Paraná. We are grateful to British Museum of Natural History and Muséum d'Histoire Naturelle, Paris, France for types images. Finally, we thank Diego S. Porto and an anonymous reviewer for comments on the manuscript that helped improve it. AL and RBG conceived the study and wrote the manuscript. AL carried out the phylogenetic analyses. 


\section{References}

Almeida EA, Porto DS (2014) Investigating eusociality in bees while trusting the uncertainty. Sociobiology 61 (4): 355-368. https://doi. org/10.13102/sociobiology.v61i4.355-368

Ascher JS, Pickering J (2021) Discover Life bee species guide and world checklist (Hymenoptera: Apoidea: Anthophila). Available from: https://www.discoverlife.org/mp/20q (07/07/2021).

Barrows EM (1973) Soil nesting by wood-inhabiting halictine bees, $A u$ gochlora pura and Lasioglossum coeruleum (Hymenoptera: Halictidae). Journal of the Kansas Entomological Society 46 (4): 496-499.

Brosi BJ, Smith-Pardo A, Gonzalez VH (2006) A new wood-nesting Neocorynura (Hymenoptera: Halictidae: Augochlorini) from Costa Rica, with notes on its biology. Zootaxa 1189: 55-68. https://doi. org/10.11646/zootaxa.1189.1.3

Cockerell TDA (1923) Some bees from British Guiana. Annual Magazine of Natural History 11 (9): 442-459.

Coelho BWT (2004) A review of the bee genus Augochlorella (Hymenoptera: Halictidae: Augochlorini). Systematic Entomology 29 (3): 282-323. https://doi.org/10.1111/j.0307-6970.2004.00243.x

Dalmazzo M, Roig-Alsina A (2011) Revision of the species of the New World genus Augochlora (Hymenoptera, Halictidae) occurring in the southern temperate areas of its range. Zootaxa 2750: 15-32. https://doi.org/10.11646/zootaxa.2750.1.2

Dalmazzo M, Roig-Alsina A (2012) Nest structure and notes on the social behavior of Augochlora amphitrite (Schrottky) (Hymenoptera, Halictidae). Journal of Hymenoptera Research 26: 17-29. https:// doi.org/10.3897/jhr.26.2440

Dalmazzo M, Roig-Alsina A (2015) Social biology of Augochlora (Augochlora) phoemonoe (Hymenoptera, Halictidae) reared in laboratory nests. Insectes sociaux 62(3): 315-323. https://doi.org/10.1007/ s00040-015-0412-8

Dalmazzo M, Roig-Alsina A (2018a) Dominant-subordinate social interactions and subordinate behavioral responses in the primitively eusocial sweat bee Augochlora phoemonoe (Hymenoptera: Halictidae). Apidologie 49(6): 852-861. https://doi.org/10.1007/s13592018-0609-8

Dalmazzo M, Roig-Alsina A (2018b) Primitively Eusocial Behavior Observed in Colonies of Augochlora amphitrite (Hymenoptera: Halictidae) Reared in Laboratory. Sociobiology 65 (4): 773-776. https://doi.org/10.13102/sociobiology.v65i4.3484

Danforth BN (2002) Evolution of sociality in a primitively eusocial lineage of bees. Proceedings of the National Academy of Sciences 99 (1): 286-290. https://doi.org/10.1073/pnas.012387999

Danforth BN, Eickwort GC (1997) The evolution of social behavior in the augochlorine sweat bees (Hymenoptera: Halictidae) based on a phylogenetic analysis of the genera. In: Choe JC, Crespi BJ (Eds) The evolution of social behavior in insects and arachnids. Cambridge University Press, Cambridge, 270-292. https://doi. org/10.1017/CBO9780511721953.014

Eickwort GC (1969) A comparative morphological study and generic revision of the augochlorine bees (Hymenoptera: Halictidae). The University of Kansas Science Bulletin 48: 325-524. https://doi. org/10.5962/bhl.part. 11227

Eickwort GC, Eickwort KR (1972) Aspects of the biology of Costa Rican halictine bees, IV. Augochlora (Oxystoglosella). Journal of the Kansas Entomological Society 45: 18-45.

Eickwort GC, Eickwort KR (1973) Notes on the nests of three wooddwelling species of Augochlora from Costa Rica (Hymenoptera: Halictidae). Journal of the Kansas Entomological Society 46: 17-22.
Eickwort GC, Sakagami SF (1979) A classification of nest architecture of bees in the tribe Augochlorini (Hymenoptera: Halictidae; Halictinae), with description of a Brazilian nest of Rhinocorynura inflaticeps. Biotropica 28-37. https://doi.org/10.2307/2388168

Eickwort GC, Eickwort JM, Gordon J, Eickwort MA, Wcislo WT (1996) Solitary behavior in a high-altitude population of the social sweat bee Halictus rubicundus (Hymenoptera: Halictidae). Behavioral Ecology and Sociobiology 38 (4): 227-233.

Engel MS (2000) Classification of the Bee Tribe Augochlorini (Hymenoptera: Halictidae). Bulletin of the American Museum of Natural History 250: 1-89. https://doi.org/10.1206/0003-0090(2000)250\%3 C0001:COTBTA\%3E2.0.CO;2

Engel MS, Hinojosa-Diaz IA, Bennett DJ (2012) New species of macrocephalic halictine bees (Hymenoptera: Halictidae). Annales Zoologici 62 (2): 297-307. https://doi.org/10.3161/000345412X652837 Genaro JA (2016) Especies nuevas y nuevos registros de abejas para las Antillas (Hymenoptera: Anthophila; Colletidae, Halictidae). Novitates Caribaea 10: 38-51. https://doi.org/10.33800/nc.v0i10.28

Gibbs J, Brady SG, Kanda K, Danforth BN (2012) Phylogeny of halictine bees supports a shared origin of eusociality for Halictus and Lasioglossum (Apoidea: Anthophila: Halictidae). Molecular Phylogenetics and Evolution 65 (3): 926-939. https://doi.org/10.1016/j. ympev.2012.08.013

Goloboff PA, Farris JS, Nixon KC (2008) TNT, a free program for phylogenetic analysis. Cladistics 24 (5): 774-786. https://doi. org/10.1111/j.1096-0031.2008.00217.x

Gonçalves RB (2016) A molecular and morphological phylogeny of the extant Augochlorini (Hymenoptera, Apoidea) with comments on implications for biogeography. Systematic Entomology 41 (2): 430-440. https://doi.org/10.1111/syen.12166

Gonçalves RB (2019) Phylogeny of the Augochlora clade with the description of four new species (Hymenoptera, Apoidea). Revista Brasileira de Entomologia 63 (1): 91-100. https://doi.org/10.1016/j. rbe.2018.12.003

Gonçalves RB, Melo GAR (2012) Phylogeny and revision of the bee genus Rhinocorynura Schrottky (Hymenoptera, Apidae, Augochlorini), with comments on its female cephalic polymorphism. Revista Brasileira de Entomologia 56: 29-46. https://doi.org/10.1590/ S0085-56262012005000011

Gonzalez VH, Stein T, Amith JD, Ayala R (2014) New record and nest description of the nocturnal sweat bee Megalopta tetewana Gonzalez, Griswold, and Ayala, 2010 (Hymenoptera: Halictidae). The Pan-Pacific Entomologist 90 (1): 40-43. https://doi. org/10.3956/2014-90.1.40

Kapheim KM, Jones BM, Pan H, Li C, Harpur BA, Kent CF, Zayed A, Ioannidis P, Waterhouse RM, Kingwell C, Stolle E, Avalos A, Zhang G, McMillan WO, Wcislo WT (2020) Developmental plasticity shapes social traits and selection in a facultatively eusocial bee. Proceedings of the National Academy of Sciences 117 (24): 13615-13625. https://doi.org/10.1073/pnas.2000344117

Kawada R, Buffington ML (2016) A scalable and modular dome illumination system for scientific microphotography on a budget. PLoS One, 11 (5): e0153426. https://doi.org/10.1371/journal.pone.0153426

Lepeco A, Gonçalves RB (2018) The Colour and the Shape: Morphological Variation on a Facultatively Eusocial Bee Augochlora (Augochlora) amphitrite (Schrottky). Sociobiology 65 (4): 662-670. https://doi.org/10.13102/sociobiology.v65i4.3388

Lepeco A, Gonçalves RB (2020a) A revision of the bee genus Augochlora Smith (Hymenoptera; Apoidea) in Southern South America. Zootaxa 4897 (1): 1-97. https://doi.org/10.11646/zootaxa.4897.1.1 
Lepeco A, Goncalves RB (2020b) New species of Augochlora (Oxystoglossella) Eickwort (Hymenoptera; Apoidea) from Northeastern Brazil with an identification key for the region. Zootaxa 4802 (2): 261-293. https://doi.org/10.11646/zootaxa.4802.2.3

Lewis PO (2001) A likelihood approach to estimating phylogeny from discrete morphological character data. Systematic biology 50 (6): 913-925. https://doi.org/10.1080/106351501753462876

Michener CD (1990) Reproduction and castes in social halictine bees. In: Engels W (Ed) Social Insects: An Evolutionary Approach to Castes and Reproduction. Springer Verlag, Berlin, 77-121.

Michener CD (2007) The Bees of the World. Second Edition. Johns Hopkins University Press, Baltimore, 953 pp.

Michener CD, Fraser A (1978) A comparative anatomical study of mandibular structure in bees. The University of Kansas Science Bulletin 51 (14): 463-482

Michener CD, Lange RB (1958) Observations on the behavior of Brazilian halictid bees, III. The University of Kansas Science Bulletin 39 (11): 473-505.

Moure JS (2012) Augochlorini Beebe, 1925. In: Moure JS, Urban D, Melo GAR (Orgs) Catalogue of Bees (Hymenoptera, Apoidea) in the Neotropical Region - online version. Available from http://www. moure.cria.org.br/catalogue (05/13/2021).

Moure JS, Hurd PD (1987) An annotated catalog of the halictid bees of the western hemisphere (Hymenoptera: Halictidae). Smithsonian Institution Press, Washington DC, 405 pp.

Nixon KC (2002) Winclada. Ver. 1.00.08. [Computer software and manual]. Published by the Author, Ithaca.

Ordway E (1965) Caste differentiation in Augochlorella (Hymenoptera, Halictidae). Insectes Sociaux, 12 (4): 291-308. https://doi org/10.1007/BF02222719

O'Reilly JE, Puttick MN, Parry L, Tanner AR, Tarver JE, Fleming J, Pisani D, Donoghue, PCJ (2016) Bayesian methods outperform parsimony but at the expense of precision in the estimation of phylogeny from discrete morphological data. Biology letters 12 (4): 20160081. https://doi.org/10.1098/rsbl.2016.0081

Pabalan N, Davey KG, Packer L (2000) Escalation of Aggressive Interactions During Staged Encounters in Halictus ligatus Say (Hymenoptera: Halictidae), with a Comparison of Circle Tube Behaviors with Other Halictine Species'. Journal of Insect Behavior 13 (5): 627-650. https://doi.org/10.1023/A:1007868725551

Packer L, Genaro JA, Sheffield CS (2007) The bee genera of eastern Canada. Canadian Journal of Arthropod Identification 3 (3): 1-32. https://doi.org/10.3752/cjai.2007.03

Packer L, Coelho BW, Mateus S, Zucchi R (2003) Behavioral interactions among females of Halictus (Seladonia) lanei (Moure)(Hymenoptera: Halictidae). Journal of the Kansas Entomological Society 76 (2): 177-182.

Pinheiro-Machado C, Alves-dos-Santos I, Imperatriz-Fonseca VL, Kleinert ADMP, Silveira FAD (2002) Pinheiro-Machado, C., Alvesdos-Santos, I., Imperatriz-Fonseca, V.L., Kleinert, A.D.M.P. \& Silveira, F.A.D. (2002) Brazilian bee surveys: state of knowledge, conservation and sustainable use. In: Kevan PG, Imperatriz-Fonseca VL (Eds) Pollinating Bees, The Conservation Link Between Agriculture and Nature. Ministério do Meio Ambiente, Brasília, 115-129.

Rambaut A, Drummond AJ, Xie D, Baele G, Suchard MA (2018) Posterior summarization in Bayesian phylogenetics using Tracer 1.7 Systematic biology 67 (5): 901-904. https://doi.org/10.1093/sysbio/ syy032

Ronquist F, Teslenko M, Van Der Mark P, Ayres DL, Darling A, Höhna S, Larget B, Liu L, Suchard MA, Huelsenbeck JP (2012) MrBayes
3.2: efficient Bayesian phylogenetic inference and model choice across a large model space. Systematic biology 61 (3): 539-542. https://doi.org/10.1093/sysbio/sys029

Rosa BB, Melo GAR, Barbeitos MS (2019) Homoplasy-based partitioning outperforms alternatives in Bayesian analysis of discrete morphological data. Systematic biology 68 (4): 657-671. https:// doi.org/10.1093/sysbio/syz001

Sakagami SF, Eickwort GC (1962) The nest architecture of the sweat bees. A comparative study of behavior. University Press of Kansas, Lawrence, $135 \mathrm{pp}$.

Sakagami SF, Moure JS (1965) Cephalic polymorphism in some Neotropical halictine bees (Hymenoptera: Apoidea). Anais da Academia Brasileira de Ciências 37: 303-313.

Sakagami SF, Munakata M (1972) Distribution and Bionomics of a Transpalaearctic Eusocial Halictine Bee, Lasioglossum (Evylaeus) calceatum, in Northern Japan, with Reference to Its Solitary Life Cycle at High Altitude (With 9 Text-figures and 2 Tables). 北海道 大學理學部紀要, 18 (3): 411-439.

Sandhouse GA (1937) The bees of the genera Augochlora, Augochloropsis and Augochlorella (Hymenoptera; Apoidea) ocurring in the United States. Journal of the Washington Academy of Sciences 27 65-79.

Santos LM, Tierney SM, Wcislo WT (2010) Nest descriptions of Megalopta aegis (Vachal) and M. guimaraesi Santos \& Silveira (Hymenoptera, Halictidae) from the Brazilian Cerrado. Revista Brasileira de Entomologia 54 (2): 332-334. https://doi.org/10.1590/S008556262010000200018

Schrottky C (1909a) Nuevos himenópteros sudamericanos. Revista del Museo de La Plata 16 (3): 137-149.

Schrottky C (1909b) Synonymische Bemerkungen über einige südamerikanisch Halictinae. *Hym.). Deutsche Entomologische Zeitschrift 109: 479-485.

Sereno PC (2007) Logical basis for morphological characters in phylogenetics. Cladistics 23 (6): 565-587. https://doi.org/10.1111/j.10960031.2007.00161.x

Silveira FA, Melo GAR, Almeida EAB (2002) Abelhas brasileiras. Sistemática e Identificação. Fundação Araucária, Belo Horizonte, $253 \mathrm{pp}$.

Smith F (1853) Catalogue of Hymenopterous Insects in the Collection of the British Museum. Part I. Andrenidae and Apidae. British Museum, London, 198 pp.

Stockhammer KA (1966) Nesting habit and life cycle of a sweet bee, Augochlora pura. Journal of the Kansas Entomological Society 39 (2): 157-192.

Wcislo WT, Danforth BN (1997) Secondarily solitary: the evolutionary loss of social behavior. Trends in Ecology and Evolution 12 (12): 468-474.

Wcislo WT, Gonzalez VH, Engel MS (2003) Nesting and social behavior of a wood-dwelling Neotropical bee, Augochlora isthmi (Schwarz), and notes on a new species, A. alexanderi Engel (Hymenoptera: Halictidae). Journal of the Kansas Entomological Society 76 (4): 588-602.

Wright AM, Hillis DM (2014) Bayesian analysis using a simple likelihood model outperforms parsimony for estimation of phylogeny from discrete morphological data. PLoS One 9 (10): e109210. https://doi.org/10.1371/journal.pone.0109210

Zillikens A, Steiner J, Mihalkó Z (2001) Nests of Augochlora (A.) esox in bromeliads, a previously unknown site for sweat bees (Hymenoptera: Halictidae). Studies on Neotropical Fauna and Environment 36 (2): 137-142. https://doi.org/10.1076/snfe.36.2.137.2133 


\section{Supplementary material 1}

\section{List of characters}

Authors: Lepeco A, Gonçalves RB (2022)

Data type: .docx

Explanation note: Besides the original characters, many were compiled - and modified, when necessary - from Eickwort (1969), Danforth \& Eickwort (1997), Engel (2000), Coelho (2004), Gonçalves (2015), Gonçalves (2016), and Gonçalves (2019).

Copyright notice: This dataset is made available under the Open Database License (http://opendatacommons.org/licenses/odbl/1.0). The Open Database License (ODbL) is a license agreement intended to allow users to freely share, modify, and use this Dataset while maintaining this same freedom for others, provided that the original source and author(s) are credited.

Link: https://doi.org/10.3897/asp.80.e71943. supp11

\section{Supplementary material 2}

\section{Character matrix and examined material}

Authors: Lepeco A, Gonçalves RB (2022)

Data type: .xlsx

Explanation note: This spreadsheet includes the matrix of characters used in all analyses and the specimens examined during morphological investigation.

Copyright notice: This dataset is made available under the Open Database License (http://opendatacommons.org/licenses/odbl/1.0). The Open Database License (ODbL) is a license agreement intended to allow users to freely share, modify, and use this Dataset while maintaining this same freedom for others, provided that the original source and author(s) are credited.

Link: https://doi.org/10.3897/asp.80.e71943. supp12

\section{Supplementary material 3}

\section{Partitioning schemes}

Authors: Lepeco A, Gonçalves RB (2022)

Data type: .docx

Explanation note: Scheme off partitions used in Bayesian analysis, based on homoplasy values calculated in the software TNT.

Copyright notice: This dataset is made available under the Open Database License (http://opendatacommons.org/licenses/odbl/1.0). The Open Database License (ODbL) is a license agreement intended to allow users to freely share, modify, and use this Dataset while maintaining this same freedom for others, provided that the original source and author(s) are credited.

Link: https://doi.org/10.3897/asp.80.e71943. suppl3 


\section{Supplementary material 4}

\section{Phylogenetic trees}

Authors: Lepeco A, Gonçalves RB (2022)

Data type: .docx

Explanation note: Supplementary phylogenetic trees showing posterior probabilities and mapped synapomorphies.

Copyright notice: This dataset is made available under the Open Database License (http://opendatacommons.org/licenses/odbl/1.0). The Open Database License (ODbL) is a license agreement intended to allow users to freely share, modify, and use this Dataset while maintaining this same freedom for others, provided that the original source and author(s) are credited.

Link: https://doi.org/10.3897/asp.80.e71943. supp14 